\title{
Development of a theory-based, peer support intervention to promote weight loss among Latina immigrants
}

\author{
Andrea L Cherrington ${ }^{1 *}$, Amanda L Willig ${ }^{2}$, April A Agne ${ }^{1}$, M Cecilia Fowler ${ }^{1}$, Gareth R Dutton ${ }^{1}$ and Isabel C Scarinci ${ }^{1}$
}

\begin{abstract}
Background: Obesity rates are disproportionately high among Latinas living in the United States. Few community-based weight management studies have focused on Latina immigrants living in emerging Latino communities. The purpose of this study was to develop and pilot test a theory-based, promotora-delivered, peer support weight loss intervention for Latina immigrants to be administered in a community setting.

We employed participatory methods to develop an 8-week program grounded in self-determination theory. Overweight Latina immigrants were recruited to participate in a quasi-experimental pilot study. Data collected pre and post-intervention included height, weight, fasting lipids, glucose, dietary practices, physical activity and depressive symptoms.
\end{abstract}

Results: Twenty-two women completed the intervention. Mean age was 36, mean time in the U.S. was 12 years; the majority was from Mexico. Mean BMI was 33; $68 \%$ had a family history of diabetes. The intervention resulted in statistically significant weight loss (mean $2.1 \mathrm{~kg}, \mathrm{SD} 2.6, \mathrm{p}<0.001$ ); mean change in weight remained significant when compared with that of a historical control group $(-2.1 \mathrm{~kg}$ vs $1.10 \mathrm{~kg}, p<0.01)$ but was attenuated at 6 months. Levels of moderate physical activity increased significantly $(p<0.05)$ and dietary practices improved $(p<0.01)$ and remained significant at 6 months. Notably, depressive symptoms also improved ( $p=<0.001)$.

Conclusions: This theory-based, promotora-delivered intervention resulted in significant weight loss among a sample of Latina immigrants at 8 weeks. Future studies are needed to test the impact of an extended peer support intervention on long-term weight management.

Trial registration: National Clinical Trials: NCT02344212. Registered 21 January 2015.

Keywords: Obesity, Latino, Peer support, Community-based participatory research, Community Health Workers, Diabetes prevention

\section{Background}

Obesity is a significant risk factor for diabetes, and modest weight loss is a key factor for diabetes prevention [1]. Obesity rates among Latinos are disproportionately high and are especially pronounced among women [2]. For example, $42 \%$ of Mexican American women are obese compared to $30 \%$ of non-Hispanic white women [3]. While Latino immigrants often arrive in the United States (U.S.) at a healthy weight, time living in the U.S.,

\footnotetext{
* Correspondence: cherrington@uab.edu

'Division of Preventive Medicine, School of Medicine, University of Alabama at Birmingham, MT 612, 1720 2nd Avenue South, Birmingham, Alabama 35294, USA

Full list of author information is available at the end of the article
}

and changes in lifestyle, diet, and physical activity, are all associated with weight gain [4-6]. Without a significant shift in current trends, it is predicted that the adult Latino population will have an over whelming diabetes prevalence at more than $20 \%$ by 2031 [7].

Geographically, most Latinos in the U.S. still live in 9 states that have large, long-standing Latino communities, however, the proportion of individuals living in other states has been growing [8]. As of 2010, 25\% of Latinos live in states other than those 9, in what may be considered "emerging Latino communities". Immigrants in newly emerging communities face unique challenges when it comes to health promotion, including underdeveloped 
social networks and limited access to education and health related resources [9]. To be effective in emerging communities, interventions should give consideration to these unique, contextual challenges; however a recent literature review identified a limited number of weight loss studies in Latino communities and not one was conducted in an emerging community [10]. Given the disproportionate growth rate of Latino immigrants in emerging communities, there is a need for weight loss interventions that are simultaneously evidence-based, as well as culturally- and contextually-sensitive to the needs of these high-risk communities, particularly the need for increased social support. A promotora-delivered peer support intervention may be the ideal way to achieve this goal. Promotoras are trusted, lay individuals from Hispanic/Latino communities who receive targeted training to provide health education and support within their communities [11]. They serve as a bridge between their own community and the health system as well as other social service organizations [12].

Although Latinos now comprise the largest minority group in the U.S., strikingly few weight management studies have focused solely on Latinos and fewer still on Latino immigrants [8]. The multi-site Diabetes Prevention Program (DPP), an intensive lifestyle intervention involving weight loss and physical activity, included 15\% Latinos in its sample of 3,234 participants [13]. While this intensive intervention reduced the risk of developing diabetes by $58 \%$ in high-risk individuals, Latinos in this study were English speaking and presumably more highly acculturated than most recent immigrants. A systematic review published in 2013 [10] identified 7 randomized controlled trials examining the effectiveness of weightloss interventions among adult Latinos living in the U.S. [14-20]. Most interventions were delivered by dieticians, nurses or other health professional; only 2 were promotoraled, a third was led by a promotora/nurse team. Results from these 2 peer-based studies are promising; however they are limited by small samples sizes (range 18 to 72). None of the trials were conducted in what might be considered emerging communities.

We developed a theory-based, promotora-delivered intervention to promote weight loss among immigrants in an emerging Latino community in Alabama. The intervention, entitled ESENCIAL Para Vivir (Essential for Life), incorporates the cultural beliefs, attitudes and perspectives of recent, mostly Mexican, Latina immigrants. Grounded in Self-Determination Theory (SDT), the intervention is delivered by a promotora and is designed to promote autonomous motivation for weightrelated behaviors by enhancing individuals' sense of autonomy, competence, and relatedness to others [21]. Below, we briefly describe the development process for this program, intervention content and theoretical underpinnings, and pilot study results.

\section{Methods}

\section{Research setting}

This study took place in Birmingham, Alabama (AL). AL has some of the highest rates of obesity in the nation with over $30 \%$ of adults classified as obese $\left(B M I>30 \mathrm{~kg} / \mathrm{m}^{2}\right)$. The state has the second highest rate $(11.1 \%)$ of adults diagnosed with diabetes [22]. Also, AL has one of the fastest growing Latino populations in the nation, with growth rates close to $200 \%$ over the past two decades; according to the 2010 census, Latinos comprise $3.6 \%$ and $4.1 \%$ of the population in Birmingham and Alabama respectively (up from $1.5 \%$ in 2000$)$ [8,23]. Even during the recent economic downturn, AL remained second in the nation for growth of the Latino immigrant population.

\section{Study protocol and procedures}

The study protocol and procedures were approved by the University of Alabama at Birmingham's Institutional Review Board. All participants provided written informed consent in their target language (English or Spanish) prior to commencing study-related measures and procedures. All study procedures comply with the Declaration of Helskini.

\section{Intervention development Advisory board}

An advisory board inclusive of all stakeholders was created to help guide the intervention development process. This board included community members, promotoras, an endocrinologist (from Mexico), a bicultural nutritionist and representative from the health department's Office of Minority Health, and a behavioral scientist with expertise in community-based methods and Latino health. The board met quarterly to review qualitative results and propose intervention strategies, content, and materials.

\section{Focus groups}

Formative work included 9 focus groups with community members and 18 semi-structured interviews with managers of peer-led programs and promotora themselves [24-26]. Focus groups revealed that culturally tailored nutrition/lifestyle programs are scarce but welcomed, provided they incorporate traditional foods and customs. Women wanted practical strategies and social support for physical activity and family involvement, including information for children and buy-in from their spouse. Promotoras reported challenges feeling confident in their role and a desire for additional resources to help address medical and health-related topics. Program managers identified issues around ensuring intervention fidelity. Themes identified were used to develop intervention strategies. 


\section{Peer leader recruitment and training}

We recruited one bilingual, bicultural promotora locally through word of mouth. Requirements for hire included good personal communication skills, a driver's license, and a desire to work in the community. For this intervention, we provided training in topics related to each session as well as basic training in communication and the principles of Motivational Interviewing (MI). MI emphasizes an individual's control and explores their ambivalence about change, and unlike traditional health education it does not rely on the delivery of untailored advice [27]. MI has been successfully implemented in weight loss interventions and is congruent with SDT and autonomous motivation (described below) [28]. Throughout training, the promotora participated in role-playing and conducted practice sessions to gain confidence with the material.

\section{Intervention content and delivery}

Data collected during the formative phase was used to develop a peer-led eight-week intervention consisting of six group sessions and two individual sessions. In response to the need for spousal and family buy-in, an orientation session and a graduation ceremony were developed and families were invited to attend. Promotoras facilitated small and large group discussions that centered on identifying personal as well as family-level values related to health and well-being [24]. Subsequent sessions were designed to be interactive and included a combination of didactic information about diabetes prevention, healthy nutrition, and physical activity promotion, as well as group and individual activities and discussions (Table 1). In addition to information provided directly by the peer leader, an educational DVD was developed as a teaching tool to deliver brief didactic health education in a fun and informative way. Additionally the DVD functioned to relieve the burden for the promotora to become the "health expert". For example, myths and misinformation were addressed during a scripted 'talk show' with two nutrition experts fielding questions from callers. Questions from participants in previous studies regarding healthy lifestyles were collected and used to develop content for the talk show. A separate physical activity DVD provided a convenient way for women to exercise at home if they felt unsafe in their neighborhood or if they were unable to find child-care.

\section{Theoretical framework of intervention}

Self-Determination Theory (SDT) was used as the theoretical foundation for the intervention [21]. SDT distinguishes between motivation that is controlled (i.e., occurs when people act because they feel pressured or compelled to do so) versus autonomous (i.e., occurs when people perceive that reasons for behavior are chosen, emanating from oneself). According to SDT, autonomously motivated behaviors are more likely to be maintained over time [21], while behaviors elicited through controlled motivation are less likely to be maintained when the incentive or threat is removed [21]. There is a growing body of evidence to support this behavior theory, particularly as it relates to lifestyle modification and weight-related behaviors [29,30].

Deci and Ryan, the founders of SDT, identified three basic psychological needs that underlie an individual's propensity towards autonomous motivation, specifically the need for autonomy, competence and relatedness to others [21]. The ESENCIAL Para Vivir intervention was designed to deliver weight loss content through peer support in a way that is autonomy supportive with an overall goal of enhancing autonomous motivation for weightrelated behaviors and ultimately promoting weight loss over the long term. Table 2 describes intervention content and peer support strategies as they relate to the psychological needs for autonomy, competence, and relatedness to others.

\section{Pilot testing}

Following development of the promotora-led intervention, Latina women were recruited to participate in pilot study of the program. Four groups of women $(n=6-10)$ were recruited from September to December 2009 through a local safety-net hospital, multicultural center, and by word-of-mouth. A bilingual research assistant screened the prospective participants for eligibility and invited them to an enrollment day. Inclusion criteria were foreign born, self-identified as Latina, no history of diagnosed diabetes, fasting blood sugar $<126 \mathrm{mg} / \mathrm{dL}$, and over-weight or obese $\left(\mathrm{BMI}>25 \mathrm{~kg} / \mathrm{m}^{2}\right)$. Additional exclusion criteria were: any medical condition for which weight loss was contraindicated; a fasting glucose $>126 \mathrm{mg} / \mathrm{dL}$, pregnancy, postpartum less than 6 months, or planning a pregnancy before the end of the study period.

\section{Data collection procedures and measurement tools}

After obtaining written consent, measurement of each participant's height, weight, fasting glucose, and a rapid lipid panel was completed. Participants also completed a questionnaire assessing demographics, health behaviors, and psychosocial constructs. Data were collected at baseline, following the 8-week intervention, and at a 6month follow-up. Weight was measured using an electronic scale (Health-O-Meter Professional 349KLX, Health-O-Meter, Boca Raton, FL). Height was measured using a portable stadiometer (Seca 217, Seca, Columbia, MD). A finger stick was completed to obtain fasting glucose (TrueResult Meter, HOMEdiagnostics, Fort Lauderdale, FL) and a rapid lipid panel (CardioChek P.A. Analyzer, CardioChek, Indianopolis, IN). Participants also answered 
Table 1 ESENCIAL Para Vivir pilot intervention content and delivery methods

\begin{tabular}{|c|c|c|c|}
\hline Session & Focus & Content & Delivery methods \\
\hline \multirow[t]{4}{*}{1} & \multirow[t]{4}{*}{ Diabetes Risk \& Prevention } & - Diabetes Risk and Prevention & DVD \\
\hline & & - Personal Values \& Your Health & Activity \\
\hline & & - Group Exercise & DVD \\
\hline & & - My Action Plan - Small Goals Towards Health & Homework \\
\hline \multirow[t]{2}{*}{2} & \multirow[t]{2}{*}{ Barriers to Healthy Living (Individual) } & - Barriers to Physical Activity \& Healthy Eating & Assessment \\
\hline & & - Setting Goals & Activity \\
\hline \multirow[t]{6}{*}{3} & \multirow[t]{6}{*}{ Bases for Healthy Eating I } & - The Food Pyramid: A guide to a healthier life & DVD \\
\hline & & - The Food Pyramid & Group Activity \\
\hline & & - A Rainbow on Our Plate & DVD \\
\hline & & - A Rainbow on Your Plate & Activity \\
\hline & & - Group Exercise & DVD \\
\hline & & - Get more colors on your plate & Homework \\
\hline \multirow[t]{6}{*}{4} & \multirow[t]{6}{*}{ Bases for Healthy Eating ॥ } & - My Plate: Choosing how much to eat & Activity \\
\hline & & - Food Labels: A guide to eating healthier & DVD \\
\hline & & - Food Labels: Identify Key Elements & Activity \\
\hline & & - Jose \& Julia: What is healthy? & DVD \\
\hline & & - Group Exercise & DVD \\
\hline & & - Practice reading food labels & Homework \\
\hline \multirow[t]{3}{*}{5} & \multirow[t]{3}{*}{ Shopping for your Health (Grocery Store) } & - Making Healthier Choices: Food label comparisons & Activity \\
\hline & & - Choosing Healthier Snacks: Is my snack healthy? & Activity \\
\hline & & Treasure Hunt & Activity \\
\hline \multirow[t]{4}{*}{6} & \multirow[t]{4}{*}{ Ways to Cook Healthier for Life } & - Cooking with Julia & DVD \\
\hline & & - How to make a healthier snack & Activity \\
\hline & & - Buying Leaner Meats & Card/Discussion \\
\hline & & - Healthier ways to season foods & Card/Discussion \\
\hline \multirow[t]{5}{*}{7} & \multirow[t]{5}{*}{ Stress Management (Individual) } & & Activity \\
\hline & & - What stresses you? & Discussion \\
\hline & & - Ways to avoid/minimize stressful situations & \\
\hline & & - Relaxation Techniques & Activity \\
\hline & & How to recognize depression & Card/Discussion \\
\hline \multirow[t]{5}{*}{8} & \multirow[t]{5}{*}{ Healthy Living for Life } & - Bases for Healthy Eating (Food Pyramid \& Reading Labels) & Review \\
\hline & & - Cooking Healthy for Life: Techniques & Review \\
\hline & & - Incorporating Physical Activity into Daily Life & Review \\
\hline & & - Diabetes Risk \& Prevention & Review \\
\hline & & - Julia \& Jose: Healthy habits for life & DVD \\
\hline
\end{tabular}

a series of questions on demographics, health status, depressive symptoms, dietary habits, and physical activity. The survey was administered in-person by a trained bilingual/bicultural interviewer in 45 minutes or less.

Depressive symptoms were assessed using the previously validated 8-item Patient Health Questionnaire (PHQ-8) [31]. The Spanish version has been previously validated [32]. Dietary practices were assessed by the Dietary Behavioral Strategies Scale (DBSS), a validated tool developed specifically for Mexican immigrants that consists of 30 items measuring dietary behaviors related to diets lower in saturated fat and higher in fiber [33]. The tool was developed to serve as a rapid assessment (checklist) of dietary behaviors and previous studies have demonstrated a high level of correlation between most DBSS items and results obtained via 24-hour recall. Response options range from 1 = never performs this behavior to $4=$ almost always performs this behavior. In addition to the DBSS, three 24-hour food recalls were conducted with each participant ( 2 weekdays, one weekend day). The 
Table 2 Intervention content and activities related to three psychological needs ${ }^{\dagger}$

\begin{tabular}{|c|c|c|}
\hline $\begin{array}{l}\text { Psychological needs underlying } \\
\text { autonomous motivation }\end{array}$ & Intervention content & Peer support strategies \\
\hline Autonomy & \multirow{2}{*}{$\begin{array}{l}\text { - Personalized feedback on current dietary practices } \\
\text { and physical activity patterns }\end{array}$} & \multirow{2}{*}{$\begin{array}{l}\checkmark \text { Promotora reinforces education \& knowledge } \\
\text { including importance of diet, physical activity } \\
\text { and self-monitoring }\end{array}$} \\
\hline \multirow[t]{3}{*}{$\begin{array}{l}\text { Feeling volitional, feeling choice } \\
\text { and responsibility for one's behavior }\end{array}$} & & \\
\hline & - Identification of personal and family values, motivators & \multirow{2}{*}{$\begin{array}{l}\text { Promotora assists with personal goal setting } \\
\text { using principles of Motivational Interviewing }\end{array}$} \\
\hline & - Individualized goal setting & \\
\hline \multirow{5}{*}{$\begin{array}{l}\text { Perceived Competence } \\
\text { Feeling that one can accomplish } \\
\text { selected behaviors and reach goals }\end{array}$} & Self-monitoring & $\checkmark$ Promotora reviews goal setting and help \\
\hline & & \\
\hline & - Activities to practice problem solving & $\checkmark$ Dietary and physical activity diaries \\
\hline & $\begin{array}{l}\text { - Hands-on-learning and activities to practice newly } \\
\text { learned skills, such as menu planning and reading } \\
\text { labels }\end{array}$ & $\begin{array}{l}\text { Promotora facilitates group discussion of } \\
\text { barriers and problem solving skills }\end{array}$ \\
\hline & - Homework activities to reinforce skills learned in class & $\begin{array}{l}\checkmark \text { Promotora provides ongoing emotional } \\
\text { support and encouragement }\end{array}$ \\
\hline \multirow{5}{*}{$\begin{array}{l}\text { Relatedness to Others } \\
\text { The need to feel understood, cared } \\
\text { for and valued by significant others }\end{array}$} & $\begin{array}{l}\text { - Encourages family discussion of shared values and } \\
\text { health related goals }\end{array}$ & $\begin{array}{l}\text { Discuss strategies to identify and reach out to } \\
\text { one's support network }\end{array}$ \\
\hline & \multirow{2}{*}{$\begin{array}{l}\text { Incorporates traditional foods and cultural practices } \\
\text { identified through participatory development process }\end{array}$} & Teach and practice stress management skills \\
\hline & & Buddy system for support and accountability \\
\hline & \multirow[t]{2}{*}{$\begin{array}{l}\text { - Peer Leader provides ongoing emotional support } \\
\text { and encouragement }\end{array}$} & $\begin{array}{l}\text { Group support for problem solving and } \\
\text { physical activity }\end{array}$ \\
\hline & & $\checkmark$ Promotora led monthly support groups \\
\hline
\end{tabular}

${ }^{\dagger}$ Psychological needs derived from Self-Determination Theory [21].

${ }^{\ddagger}$ SMART = Sustainable, Measureable, Attainable, Realistic, Timely.

24-hour recalls were gathered by bilingual trained interviewers using a standardized multiple-pass interview approach with Nutrition Data System for Research (NDSR), a computer based software application [34]. Physical activity was assessed two ways. Self-reported physical activity was assessed using the Global Physical Activity Questionnaire (GPAQ), a validated measure that has been used in a number of different countries, including among Latinos living in the U.S. [35]. Participants were also given an MTI Actigraph accelerometer to wear for 4 days (3 weekday and 1 weekend day; GT1M, ActiGraph Health Services, Pensacola, FL).

For comparison, we obtained data from a medical chart review to create a historical control group. We obtained a list of all Latinas seen at the clinic over the same period as recruitment for the intervention. Using the chronological list, we reviewed every $10^{\text {th }}$ chart, selecting women who were Spanish speaking, overweight or obese without diabetes, not pregnant or post-partum, and who had a second weight recorded between 8-12 weeks from baseline. This resulted in a group of 19 women.

\section{Statistical analysis}

Descriptive statistics of all participants versus participants who completed the intervention were analyzed using $t$-tests for continuous variables and chi-square or Fisher's exact test for categorical variables. Pre-post intervention data was compared with paired $t$-tests or Fisher's exact test (depression). All analyses were completed using SAS statistical software version 9.2 (SAS Institute, Cary, NC, 2002) with a significance level established at $\mathrm{P}<0.05$.

\section{Results}

Of 35 women who initially enrolled in the program, 28 completed the program, and 26 were available for 6month follow-up for a retention rate of $75 \%$. Twentytwo women had complete biometric data at 8 weeks (4 women had incomplete accelerometer and/or 24-hour food recalls), and 21 women had complete data at 6 months. Analyses are presented for women with complete biometric data. Demographic characteristics of both women who enrolled as well as women who had complete biometric data are summarized in Table 3.

Of note, women who reported having been told by their doctor to lose weight were significantly more likely to complete the program.

\section{Physiologic outcomes}

After the 8-week intervention, mean weight decreased significantly from $83.3 \mathrm{~kg}$ to $81.1 \mathrm{~kg}$ (i.e., 4.6-lb weight loss), and mean BMI decreased from 32.7 to $31.8, p<0.001$ (Table 4). Eighty percent of participants lost weight after 8 weeks (Figure 1). Mean change in weight was statistically significant when compared with mean change in 
Table 3 Participants' demographic characteristics, family history of diabetes, weight and body mass index, and depressive symptoms

\begin{tabular}{|c|c|c|}
\hline & $\begin{array}{l}\text { All Participants } \\
(\mathrm{n}=35)\end{array}$ & $\begin{array}{l}\text { Participants with } \\
\text { complete data }{ }^{\dagger} \\
(\mathrm{n}=22)\end{array}$ \\
\hline Demographic characteristics & $N(\%)$ & $\mathrm{N}(\%)$ \\
\hline Mean Age (SD) & $37.7(8.3)$ & $36.5(7.5)$ \\
\hline \multicolumn{3}{|l|}{ Education completed } \\
\hline Less than High School & $27(77)$ & $16(73)$ \\
\hline \multicolumn{3}{|l|}{ Marital status (\%) } \\
\hline $\begin{array}{l}\text { Married/Living together } \\
\text { as married }\end{array}$ & $28(80)$ & $19(86)$ \\
\hline \multicolumn{3}{|l|}{ Employment (\%) } \\
\hline Full or part time & $18(51)$ & $12(55)$ \\
\hline Health Insurance (\%) & $5(14)$ & $3(14)$ \\
\hline \multicolumn{3}{|l|}{ Country of origin } \\
\hline Mexico & $30(86)$ & $18(82)$ \\
\hline El Salvador & $3(9)$ & $2(9)$ \\
\hline Costa Rica & $2(5)$ & $2(9)$ \\
\hline Mean Years in U.S. (SD) & $12.6(5.8)$ & $12.2(4.9)$ \\
\hline Mean Years in A.L. (SD) & $9.9(4.8)$ & $10.5(4.7)$ \\
\hline \multicolumn{3}{|l|}{ Self-rated health (\%) } \\
\hline Excellent/good & $17(49)$ & $11(50)$ \\
\hline Fair/poor & $18(51)$ & $11(50)$ \\
\hline Family history of diabetes (\%) & $24(69)$ & $15(68)$ \\
\hline Child birth weight $>91 \mathrm{bs}$ & $13(38)$ & $8(38)$ \\
\hline \multicolumn{3}{|l|}{ Anthropometric measures } \\
\hline Mean Height (cm; SD) & $158.6(5.8)$ & $159.2(5.5)$ \\
\hline Mean Weight (kg; SD) & $82.9(13.9)$ & $83.3(14.5)$ \\
\hline Mean BMI (SD) & $32.9(4.8)$ & $32.7(4.7)$ \\
\hline Told by MD to lose weight & $18(51)$ & $14(64)^{\ddagger}$ \\
\hline \multicolumn{3}{|l|}{ Depressive symptoms (\%) } \\
\hline No symptoms & $13(37)$ & $5(23)$ \\
\hline Minimal & $16(46)$ & $13(59)$ \\
\hline Moderate/severe & $6(17)$ & $4(18)$ \\
\hline
\end{tabular}

${ }^{\dagger}$ Participants $(n=22)$ with complete data for baseline, 8 weeks, and 6-month follow-up.

${ }^{\ddagger} \mathrm{P}<0.05$ for $\mathrm{n}=35$ versus $\mathrm{n}=22$.

weight for the historical control group $(-2.10 \mathrm{~kg}$ vs $1.10 \mathrm{~kg}, \mathrm{p}<0.01)$. Intervention weight change at month 6 was not significantly different from baseline, as participants demonstrated modest weight regain following treatment (Table 4). Statistically significant decreases in total cholesterol and LDL were observed at 8 weeks, $p<0.001$. At month 6, reductions in LDL remained significant, and mean HDL improved significantly at month 6 as well, $p<0.03$. Paradoxically, mean fasting glucose increased by approximately $6 \mathrm{mg} / \mathrm{dL}$ at week 8 , but the change was no longer significant at month 6 .

\section{Behavioral outcomes}

At baseline, the average caloric intake was 2,066 kilocalories with $31 \%$ of kilocalories coming from fat, 53\% coming from carbohydrates and 16\% coming from protein (Table 4). At the end of treatment, there was a significant decrease of $486 \mathrm{kcal} /$ day and a significant increase in the percentage of calories coming from protein sources, $p<0.006$. These changes in caloric and protein intake remained significant at month 6 . Healthy dietary practices increased from a mean of 2.45 (SD 0.46) at baseline to 3.14 (SD 0.44) at 8 weeks and the increase persisted at 6 months. Participants' self-reported minutes spent in moderate to vigorous activity increased at 8 weeks and remained significant at 6 months. While accelerometer data did not demonstrate a significant change in minutes of moderate to vigorous activity at 8 weeks, it did demonstrate a significant increase at 6 months $(\mathrm{p}<0.02)$. Women's depressive symptoms also improved, with the proportion of those without any depressive symptoms increasing from $23 \%$ at baseline to $73 \%$ $(\mathrm{p}<0.001)$ at 8 weeks and $80 \%$ at 6 months $(\mathrm{p}<0.001)$.

\section{Discussion}

Informed by community-based participatory methods involving local stakeholders and formative work with the target population, we successfully developed and pilot tested a theory-based, promotra-delivered weight loss intervention for Latina immigrants in an emerging community in the Southeastern U.S. The intervention resulted in statistically significant weight losses of $2.0 \mathrm{~kg}$ and $80 \%$ of women lost weight. Levels of moderate physical activity (PA) increased significantly post-intervention and at the six-month follow-up, though there was significant discrepancy between self-reported PA and more objective measurement via accelerometers. This could relate to an increased awareness about the recommendations for PA leading to more pronounced improvements by selfreport than accelerometer, or so-called response bias. Dietary practices also improved and remained significantly better at 6 months. Finally, depressive symptoms improved significantly. This pilot study demonstrates that peer support may be an appropriate mechanism for the provision of evidence-based weight loss strategies in emerging Latino communities.

A number of peer support models exist, and reviews of the evidence suggest there are common, key functions of successful peer support [36]. These include assistance with implementation of daily self-management plans tailored to the specifics of individuals' lives, provision of ongoing social and emotional support, and linkage to resources [36]. Social support in particular has been identified as a key factor in the success of weight loss and weight loss maintenance, especially for women [37,38]. In addition to its impact on weight and weight related 
Table 4 Change in physiologic and behavioral outcomes at 8 weeks and 6-month follow-up

\begin{tabular}{|c|c|c|c|c|c|}
\hline & Baseline $^{\dagger}(n=22)$ & 8-weeks $(n=22)$ & p-value & $6-$ month $^{\ddagger}(n=21)$ & p-value \\
\hline & Mean(SD) or $\mathrm{N}(\%)$ & Mean(SD) or $\mathrm{N}(\%)$ & & Mean(SD) or $\mathrm{N}(\%)$ & \\
\hline \multicolumn{6}{|l|}{ Physiologic outcomes } \\
\hline Weight (kg) & $83.3(14.5)$ & $81.2(14.0)$ & 0.001 & $82.2(14.2)$ & 0.167 \\
\hline BMI & $32.7(4.7)$ & $31.8(4.8)$ & $<0.001$ & $32.2(4.9)$ & 0.061 \\
\hline \multicolumn{6}{|l|}{ Lipids (mg/dL) } \\
\hline Total cholesterol & $202.9(55.3)$ & $176.1(52.5)$ & $<0.001$ & $195.7(73.8)$ & 0.328 \\
\hline LDL & $136.2(45.3)$ & $97.5(41.1)$ & $<0.001$ & $103.1(52.5)$ & 0.002 \\
\hline $\mathrm{HDL}$ & $45.9(4.1)$ & $46.6(14.2)$ & 0.524 & $52.4(15.5)$ & 0.023 \\
\hline Fasting glucose (mg/dL) & $93.2(11.2)$ & $99.0(14.3)$ & 0.007 & $96.0(12.4)$ & 0.186 \\
\hline \multicolumn{6}{|l|}{ Behavioral outcomes } \\
\hline Dietary practices & $2.45(0.46)$ & $3.14(0.44)$ & $<0.001$ & $3.09(0.49)$ & $<0.001$ \\
\hline \multicolumn{6}{|l|}{ Caloric intake } \\
\hline Total kcal & $2066.4(731.9)$ & $1580.6(372.8)$ & 0.006 & $1460.8(366.9)$ & $<0.001$ \\
\hline$\%$ Fat & $31(6)$ & $28(10)$ & 0.243 & $28(7)$ & 0.155 \\
\hline \%Carbohydrate & $53(8)$ & $53(9)$ & 0.984 & $53(8)$ & 0.614 \\
\hline \%Protein & $16(3)$ & $19(3)$ & $<0.001$ & $19(4)$ & 0.002 \\
\hline \multicolumn{6}{|c|}{ Moderate/Vigorous PA", minutes (median) } \\
\hline Self-report & $33.2(11.8)$ & $80.3(60.0)$ & 0.004 & $87.5(29.3)$ & 0.026 \\
\hline Accelerometer & $12.1(7.7 .1)$ & $14.5(13.3)$ & 0.464 & $39.5(16.8)$ & 0.291 \\
\hline Depressive symptoms (\%) & & & $<0.001$ & & $<0.001$ \\
\hline No symptoms & $5(23 \%)$ & $15(72 \%)$ & & $17(80 \%)$ & \\
\hline Minimal & $13(59 \%)$ & $3(14 \%)$ & & $2(10 \%)$ & \\
\hline Moderate/severe & $4(18 \%)$ & $3(14 \%)$ & & $2(10 \%)$ & \\
\hline
\end{tabular}

${ }^{\dagger}$ Of 26 participants, 22 participants had complete data for baseline, 8-weeks, and 6-month follow-up.

${ }^{\ddagger}$ One participant was excluded due to pregnancy at 6-month follow-up.

"PA = Physical Activity.

behaviors in this sample, our peer support intervention also produced a dramatic reversal of depressive symptoms. This improvement may be in part due to the increased social support and decreased isolation that peer support interventions have to offer. In contrast to established immigrant receiving communities, immigrants in newly emerging communities face unique challenges when it comes to health promotion, including immature social networks and limited access to education and health related resources [23,39]. Our own qualitative studies have demonstrated that women in these communities are often socially isolated with few outlets for engagement [24]. Thus, peer-delivered interventions may be particularly well suited to the needs of immigrant women in newly emerging Latino communities.

To our knowledge, this is the first communitybased weight loss program designed for Latino immigrants rooted in self-determination theory (SDT) [21]. SDT is a particularly appealing behavioral theory for weight management programs because of the potential it holds for promoting long-term behavior change and its intuitive overlap with peer-based programs. To date, maintenance of weight loss beyond the initial intervention phase has proven to be a challenge [40]. According to SDT, behaviors that are autonomously motivated are more likely to be maintained in the long term [21]. An increasing number of studies provide evidence for the link between autonomous motivation and satisfaction of three psychological needs, namely autonomy, perceived competence and relatedness to others $[29,41]$. To the extent that peer support can facilitate satisfaction of those three needs, it may provide an effective means of delivering evidence and theory based weight loss interventions in communitybased settings. Future studies are needed to better elucidate the mechanisms through which peer support exerts its effects, including potential influences on autonomous motivation for weight related behaviors in special populations.

To be effective in diverse communities, behavioral interventions need to include theory based, evidence- 


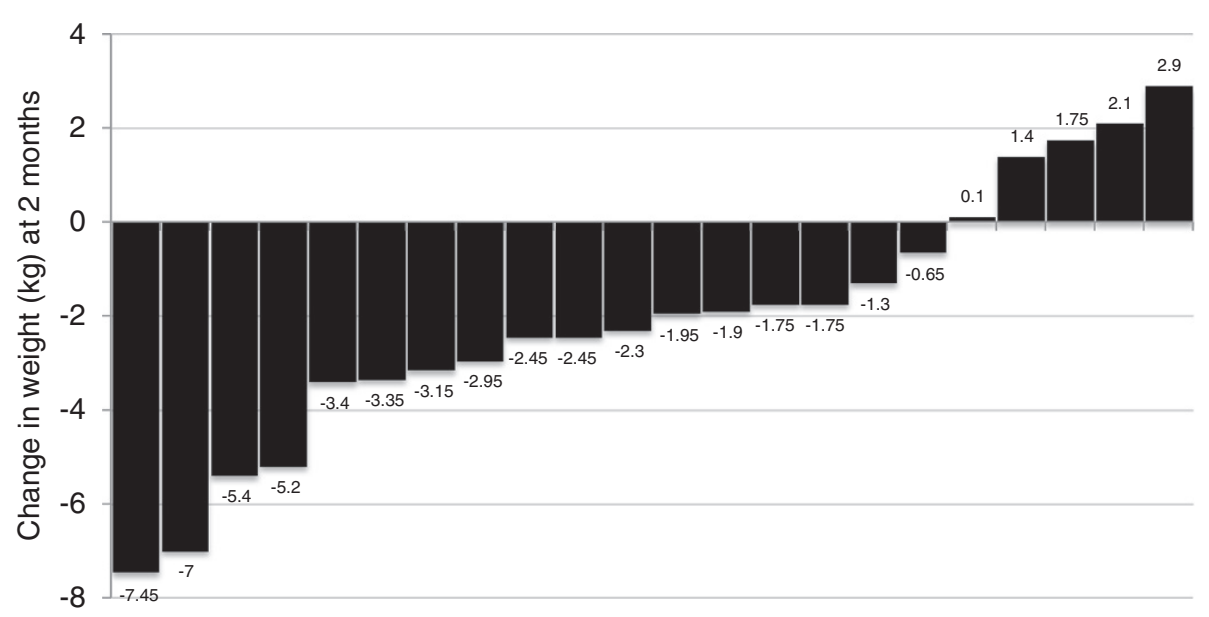

Figure 1 Individual changes in weight $(\mathbf{k g})$ from baseline to $\mathbf{2}$-month follow-up ( $\mathbf{n}=\mathbf{2 2}$ )t. +Participants ( $\mathrm{n}=26)$ completed program, only ( $n=22)$ had complete data for baseline, 2-month and 6-month follow-up.

based strategies, but they must also resonate with the intended audience. With SDT in place as a theoretical framework, we employed community-based participatory methods to develop an intervention that is culturally relevant for Latina immigrants living in Alabama and emerging communities like it. Qualitative formative work allowed us to identify factors related to surface structure sensitivity, such as preferences regarding language, terminology, presentation style, and traditional food selection, as well as deep structure sensitivity, such as the importance of family, spousal buy-in, social isolation perceived discrimination and the need for social support. By definition, community-based health interventions should be culturally and contextually specific. Our pilot study suggests that SDT may provide a theoretical foundation for community-based weight loss programs that can then be made culturally relevant through the use of participatory methods during the development phase.

Despite the innovation and other strengths of this project, several limitations should be noted. By design, this involved a pilot study with a small number of women. Despite the small sample size, significant effects in a number of clinical, behavioral, and psychosocial outcomes were observed, providing justification for continued investigation of these types of programs with larger samples. Unfortunately, weight loss findings in this study were not significant at 6 months. This result is not surprising since studies have consistently demonstrated that without some structured maintenance program, weight regain is the norm $[42,43]$. Maintenance sessions were outside the scope of the current pilot but will be an essential component of future investigations examining the longer-term outcomes of culturally adapted interventions such as the one described here. Since the sample included mostly Mexican immigrants, results may not generalize to other Latino populations.

\section{Conclusion}

The approaches applied in this study provide encouraging results regarding the potential utility and efficacy of a promotora-led weight loss intervention for Latina immigrants. Despite a relatively brief (i.e., 8-week) intervention, women demonstrated significant improvements in weight, lipids, dietary intake, physical activity, and depressive symptoms. In addition, some of these improvements were maintained at a six-month follow-up. Results from this pilot study can be used to inform future studies in the areas of measurement (i.e self-reported physical versus objective measurement), intervention content (i.e need for inclusion of maintenance sessions to promote sustained weight loss), as well as target outcomes (i.e. assessment of changes in depressive symptoms in addition to behavioral and physiologic outcomes). Additionally, future studies should assess whether an extended peer support intervention based on self-determination theory can lead to long-term weight management.

\section{Competing interests \\ The authors declare that they have no competing interests.}

\section{Authors' contributions}

ALC, ICS, ALW and AAA made substantial contributions to conception and design, and acquisition of data analysis and interpretation of data. ALC and ICS conceived of the study and participated in its design. ALC, ICS, AAA, and GRD participated in its design, coordination and helped to draft the manuscript. AAA, MCF and ALW participated in acquisition of data, analysis and interpretation of data. ALC, ICS, ALW, AAA, and GRD were involved in drafting the manuscript, reviewing and revising it critically. ALC and AAA were involved in critically reviewing and revising the manuscript. All authors read and approved the final manuscript.

\section{Acknowledgments}

This work was made possible by grants from the Robert Wood Johnson Physician Faculty Scholars' Program [047948] (Dr. Cherrington), and the National Institutes of Health, National Institute of Diabetes and Digestive and Kidney Diseases, the University of Alabama at Birmingham's Diabetes Research Center [P30 DK079626]. The authors wish to thank the women who participated in our program and all our support staff who made this work possible. 


\section{Author details}

${ }^{1}$ Division of Preventive Medicine, School of Medicine, University of Alabama at Birmingham, MT 612, 1720 2nd Avenue South, Birmingham, Alabama 35294, USA. Division of Infectious Diseases, School of Medicine, University of Alabama at Birmingham, BBRD 207, 1720 2nd Avenue South, Birmingham, Alabama 35294, USA.

\section{Received: 15 August 2014 Accepted: 24 February 2015} Published online: 19 March 2015

\section{References}

1. Hamman RF, Wing RR, Edelstein SL, Lachin JM, Bray GA, Delahanty L, et al. Effect of weight loss with lifestyle intervention on risk of diabetes. Diabetes Care. 2006;29:2102-7.

2. Mokdad AH, Ford ES, Bowman BA, Dietz WH, Vinicor F, Bales VS, et al. Prevalence of obesity, diabetes, and obesity-related health risk factors. Jama. 2003:289:76-9.

3. Ogden CL, Carroll MD, Curtin LR, McDowell MA, Tabak CJ, Flegal KM. Prevalence of overweight and obesity in the United States, 1999-2004. Jama. 2006:295:1549-55.

4. Benavides-Vaello S. Cultural influences on the dietary practices of Mexican Americans: a review of the literature. Hispanic Health Care Int. 2005:3:27-35.

5. Kaplan MS, Huguet N, Newsom JT, McFarland BH. The association between length of residence and obesity among Hispanic immigrants. Am J Prev Med. 2004;27:323-6.

6. Perez-Escamilla R, Putnik $P$. The role of acculturation in nutrition, lifestyle, and incidence of type 2 diabetes among Latinos. J Nutr. 2007;137:860-70.

7. Mainous 3rd AG, Baker R, Koopman RJ, Saxena S, Diaz VA, Everett CJ, et al. Impact of the population at risk of diabetes on projections of diabetes burden in the United States: an epidemic on the way. Diabetologia. 2007:50:934-40.

8. Passel J, Cohen D, Hugo-Lopez M. Hispanics Account for More than Half of Nation's Growth in Past Decade. Washington, DC: Pew Hispanic Center; 2011.

9. Amirehsani K. Mexican Americans with type 2 diabetes in an emerging Latino community: evaluation of health disparity factors and interventions. Home Health Care Manage Practice. 2010;22:470-8.

10. Perez LG, Arredondo EM, Elder JP, Barquera S, Nagle B, Holub CK. Evidencebased obesity treatment interventions for Latino adults in the U.S.: a systematic review. Am J Prev Med. 2013:44:550-60.

11. Elder JP, Ayala GX, Parra-Medina D, Talavera GA. Health communication in the Latino community: issues and approaches. Annu Rev Public Health. 2009;30:227-51.

12. Ayala GX, Vaz L, Earp JA, Elder JP, Cherrington A. Outcome effectiveness of the lay health advisor model among Latinos in the United States: an examination by role. Health Educ Res. 2010;25:815-40.

13. Knowler WC, Barrett Connor E, Fowler SE, Hamman RF, Lachin JM, Walker $E A$, et al. Reduction in the incidence of type 2 diabetes with lifestyle intervention or metformin. N Engl J Med. 2002;346:393-403.

14. Avila P, Hovell MF. Physical activity training for weight loss in Latinas: a controlled trial. Int J Obes Relat Metab Disord. 1994;18:476-82.

15. Cousins JH, Rubovits DS, Dunn JK, Reeves RS, Ramirez AG, Foreyt JP. Family versus individually oriented intervention for weight loss in Mexican American women. Public Health Rep. 1992;107:549-55.

16. Foucher MA, Mobley J. A community intervention on portion control aimed at weight loss in low-income Mexican American women. J Midwifery Women's Health. 2010:55:60-4.

17. Keller CS, Cantue A. Camina por Salud: walking in Mexican-American women. Appl Nurs Res. 2008;21:110-3.

18. Parikh P, Simon EP, Fei K, Looker H, Goytia C, Horowitz CR. Results of a pilot diabetes prevention intervention in East Harlem, New York City: Project HEED. Am J Public Health. 2010;100 Suppl 1:S232-239.

19. Poston 2nd WS, Haddock CK, Olvera NE, Suminski RR, Reeves RS, Dunn JK, et al. Evaluation of a culturally appropriate intervention to increase physical activity. Am J Health Behav. 2001;25:396-406.

20. West DS, Elaine Prewitt T, Bursac Z, Felix HC. Weight loss of black, white, and hispanic men and women in the diabetes prevention program. Obesity (Silver Spring). 2008;16:1413-20.

21. Ryan RM, Deci EL. Self-determination theory and the facilitation of intrinsic motivation, social development, and well-being. Am Psychol. 2000;55:68-78.
22. Centers for Disease Control and Prevention. Diabetes Report Card 2012. Atlanta, GA: Centers for Disease Control and Prevention, US Department of Health and Human Services; 2012

23. Kochlar R, Suro R, Tafoya S. The New Latino South: the Context and Consequences of Rapid Population Growth. Washington, DC: Pew Hispanic Center; 2005.

24. Agne AA, Daubert R, Munoz ML, Scarinci I, Cherrington AL. The cultural context of obesity: exploring perceptions of obesity and weight loss among Latina immigrants. J Immigr Minor Health. 2012;14(6):1063-70.

25. Cherrington A, Agne A, Munoz M, Scarinci I. Challenges faced by community health workers engaged in programs for Latino immigrants in the southeastern united states. Ann Behav Med (published abstract). 2011:41(1Supp):s216.

26. Cherrington A, Ayala GX, Amick H, Allison J, Corbie Smith G, Scarinci I. Implementing the community health worker model within diabetes management: challenges and lessons learned from programs across the United States. Diabetes Educ. 2008;34:824-33.

27. Miller WRRS. Motivational Interviewing: Preparing People to Change Addictive Behavior. New York: Guilford Press; 1991

28. West DS, Gorin AA, Subak LL, Foster G, Bragg C, Hecht J, et al. A motivationfocused weight loss maintenance program is an effective alternative to a skill-based approach. Int J Obesity (2005). 2011;35:259-69.

29. Silva MN, Markland D, Minderico CS, Vieira PN, Castro MM, Coutinho SR, et al. randomized controlled trial to evaluate self-determination theory for exercise adherence and weight control: rationale and intervention description. BMC Public Health. 2008:8:234

30. Teixeira PJ, Silva MN, Mata J, Palmeira AL, Markland D. Motivation, selfdetermination, and long-term weight control. Int J Behav Nutr Phys Act 2012;9:22.

31. Kroenke K, Strine TW, Spitzer RL, et al. The PHQ-8 as a measure of current depression in the general population. J Affect Disord. 2009;114:163-73.

32. Reuland DS, Cherrington A, Watkins GS, Bradford DW, Blanco RA, Gaynes BN. Diagnostic accuracy of Spanish language depression-screening instruments. Ann Fam Med. 2009;7:455-62.

33. Kristal AR, Abrams BF, Thornquist MD, Disogra L, Croyle RT, Shattuck AL, et al. Development and validation of a food use checklist for evaluation of community nutrition interventions. Am J Public Health. 1990:80:1318-22.

34. Johnson RK, Driscoll P, Goran MI. Comparison of multiple-pass 24-hour recall estimates of energy intake with total energy expenditure determined by the doubly labeled water method in young children. J Am Diet Assoc. 1996:96:1140-4.

35. Bull FC, Maslin TS, Armstrong T. Global physical activity questionnaire (GPAQ): nine country reliability and validity study. J Phys Act Health. 2009;6:790-804.

36. Boothroyd Rl, Fisher EB. Peers for progress: promoting peer support for health around the world. Fam Pract. 2010:27 Suppl 1:i62-8.

37. Elfhag $\mathrm{K}$, Rossner $\mathrm{S}$. Who succeeds in maintaining weight loss? A conceptual review of factors associated with weight loss maintenance and weight regain. Obes Rev. 2005;6:67-85.

38. Gorin A, Phelan S, Tate D, Sherwood N, Jeffery R, Wing R. Involving support partners in obesity treatment. J Consult Clin Psychol. 2005;73:341-3.

39. Shattell M, Villalba J, Stokes N, Hamilton D, Foster J, Petrini H, et al. Depression in Latinas residing in emerging Latino immigrant communities in the United States. Hispanic Health Care Int. 2009;7:190-202.

40. Wadden TA, Crerand CE, Brock J. Behavioral treatment of obesity. Psychiatr Clin North Am. 2005;28:151-70.

41. Williams GC, Grow VM, Freedman ZR, Ryan RM, Deci EL. Motivational predictors of weight loss and weight-loss maintenance. J Pers Soc Psychol. 1996;70:115-26.

42. Perri MG. Improving maintenance in behavioral treatment. In: Brownell CCFKD, editor. Eating Disorders and Obesity Treatment. 2nd ed. New York, NY: Guilford Press; 2002.

43. Wadden TA, Butryn ML, Byrne KJ. Efficacy of lifestyle modification for long-term weight control. Obes Res. 2004;12(Suppl):151S-62. 